\title{
Generation of haploid spermatids from chicken embryonal primordial germ cells
}

\author{
MENG $\mathrm{JI}^{1^{*}}$, SHUANG TANG ${ }^{2 *}$, WENHUA PEI ${ }^{1}$, MINGMING NING ${ }^{1}$, \\ YUEHUI MA ${ }^{1}$, XIANGCHEN LI ${ }^{1}$ and WEIJUN GUAN ${ }^{1}$ \\ ${ }^{1}$ Institute of Animal Science, Chinese Academy of Agricultural Sciences, Beijing 100193; \\ ${ }^{2}$ Liaoning Provincial Key Laboratory for Agricultural Biotechnology, College of Biological Science and Technology, \\ Shenyang Agricultural University, Shenyang, Liaoning 110866, P.R. China
}

Received December 25, 2015; Accepted January 10, 2018

DOI: $10.3892 / \mathrm{ijmm} .2018 .3602$

\begin{abstract}
In vitro production of functional spermatids has special significance in the research of spermatogenesis and the treatment of male infertility. Primordial germ cells (PGCs) are the precursors of oocyte and sperm, which generate the totipotent cells. Studies have shown that PGCs have the potential ability to develop meiotic spermatids in vitro. Here we have shown that retinoic acid (RA) leads to PGC differentiation, and SCF can improve the efficiency of induction. We indicate an efficient approach to produce haploid spermatids from chicken PGCs in the presence of RA and stem cell factor (SCF). Real-time RT-PCR assays showed that RA and SCF induced a remarkable increase in expression of SYCP1, ACR, BOULE and DCM1 of meiotic germ cells and haploid germ cells, respectively. DNA content assays revealed that RA and SCF induced a remarkable increase of haploid cells. This study provides a theoretical basis and a great animal model for spermatogenesis study.
\end{abstract}

\section{Introduction}

Germ cell can generate sperm and oocyte which are the basis for sexual reproduction (1). To produce a functional sperm, an unformed male germ cell undergoes a coordinated set of events that are collectively called spermatogenesis. In many animals, sperm cells are derived from a first germline cell population of primordial germ cells (PGCs) that are set aside

Correspondence to: Dr Xiangchen Li or Professor Weijun Guan, Institute of Animal Science, Chinese Academy of Agricultural Sciences, Beijing 100193, P.R. China

E-mail: xcli863@126.com

E-mail: wjguan86@iascaas.net.cn

${ }^{*}$ Contributed equally

Key words: spermatogenesis, chicken, primordial germ cells, retinoic acid, stem cell factor, in vitro early in embryogenesis (2,3). In the male gonads, PGCs initiate differentiation toward spermatogenesis.

For more than a century, researchers have been focusing on spermatogenesis in vitro (4). Previous studies have indicated that retinoic acid (RA) can trigger differentiation of GS cells $(5,6)$. RA, the active derivative of vitamin A, controls the entry of germ cells into meiosis in avian, mice and humans $(1,7,8)$. It has been demonstrated that RA and stem cell factor (SCF) are crucial for the maintenance of normal spermatogenesis in rodents and human spermatogonial stem cells (SSCs) $(6,9)$. SCF has been evidenced to induce human and mouse SSCs to differentiate into haploid spermatids in vitro $(6,10)$ and the $\mathrm{SCF} / \mathrm{KIT}$ system plays key role in SSC proliferation and entrance meiosis (11). Moreover, RA has been indicated to trigger germ cell meiotic origination in the chicken (12). Unfortunately, there is no evidence showing the functions of SCF in induction of PGCs spermatogenesis. Therefore, RA and SCF were chosen in this study to induce the differentiation of chicken PGCs.

In this study, we successfully generated haploid spermatids by RA and SCF inducing chicken PGCs directly in vitro. We have indicated that RA leads to PGC differentiation, and SCF can improve the efficiency of induction. In addition to providing an in vitro model for chicken PGC spermatogenesis through RA and SCF stimulation. Our results support the recent protocol that RA can trigger germ cell differentiation without somatic testicular cells (13). Our results demonstrated that chicken PGCs could be induced into male gametes. It may be a great animal model for study of spermatogenesis. We have built an efficient proposal to induce haploid spermatids in vitro, it could provide abundant operating materials for spermatozoal function research promoting the use of stem cell transplanting engineering in clinical infertility.

\section{Materials and methods}

Experimental animals. All the animal procedures were approved by the Institutional Animal Care and Use Committee of Chinese Academy of Agricultural Sciences. Chicken embryos were provided by the Experimental Animal Base Institute of Animal Sciences, Chinese Academy of Agricultural Sciences, Beijing, China. The use of animals in research and 
all experimental procedures involving chicken embryos were conducted in accordance with the guidelines established by the Institutional Animal Care and Use Committee at the University of Medicine and Dentistry of New Jersey-Robert Wood Johnson Medical School.

Isolation and in vitro culture of chicken PGCs. Fertile eggs were incubated at $38^{\circ} \mathrm{C}$ and $50 \%$ humidity for 5.5 day. Gonads of the chicken embryos developed at stage 28 (14), were isolated using stereoscopic microscope, then embryonic gonadal tissues were collected and dissociated with $0.125 \%$ trypsin- $0.02 \%$ ethylenediaminetetraacetic acid (EDTA). After neutralized with Dulbecco's modified Eagle's medium (DMEM) containing $10 \%$ fetal bovine serum (FBS), the gonadal cells were collected by centrifugation.

The precipitated cells were re-suspended in PGC cell culture medium, which consisted of DMEM medium replenished with 10\% FBS (Gibco, Grand Island, NY, USA), $2 \%$ chicken serum and supplemented with $10 \mathrm{ng} / \mathrm{ml}$ of human SCF (hSCF), $10 \mathrm{U} / \mathrm{ml}$ of leukemia inhibitory factor (LIF), $20 \mathrm{ng} / \mathrm{ml}$ of human basic fibroblast growth factor (bFGF) (all from PeproTech, London, UK), 1X penicillin/streptomycin (Life Technologies, Grand Island, NY, USA). Cell suspensions were seeded into 6-well culture plates with chicken embryonic fibroblasts (CEFs) as feeding layer (15) at a density of $1 \times 10^{4} /$ well, and cultured at $37.5^{\circ} \mathrm{C}$ in $5 \% \mathrm{CO}_{2}$. The PGC colonies were dissociated and moved into fresh plates with CEFs using trypsin-EDTA treatment for subculture (16).

Embryonic tissue collection. Following separation of the embryonic gonadal tissues respectively, $\sim 10 \mathrm{mg}$ of embryonic tissue was collected and placed in $10 \mathrm{ml}$ of digestion buffer (10 mM Tris, $1 \mathrm{mM}$ EDTA, 1\% SDS, pH 8.0 containing $10 \mathrm{mg} / \mathrm{ml}$ Proteinase-K) and incubated overnight at $45^{\circ} \mathrm{C}$. Samples were cooled to $4^{\circ} \mathrm{C}$ and centrifuged at $12,000 \mathrm{rpm}$ for $10 \mathrm{~min}$. The supernatant was transferred to a fresh microcentrifuge tube, diluted to $200 \mu \mathrm{l}$ with water and used in PCR reactions.

PAS staining and alkaline phosphatase activity assay. For PAS staining, the cell colonies of the cultured chicken PGCs were fixed with $4 \%$ paraformaldehyde for $20 \mathrm{~min}$ and washed $3 \times 5$ min with phosphate-buffered saline (PBS). The cell colonies were then submerged to periodic acid solution (Sigma-Aldrich, St. Louis, MO, USA) for $5 \mathrm{~min}$ at room temperature. After washing twice with PBS, the cell colonies were immersed in Schiff's solution (Sigma-Aldrich) for $15 \mathrm{~min}$ at room temperature. Then PAS-stained PGC colonies were observed under an inverted microscope after washing twice with PBS. Alkaline phosphatase (AKP) activity was detected by AKP substrate kit (Sigma-Aldrich) according to the manufacturer's instruction. Images were captured with a computer-assisted video camera (IX-71 inverted research microscope; Olympus, Tokyo, Japan).

Karyotyping. The chicken PGCs were incubated in $0.5 \mu \mathrm{g} / \mathrm{ml}$ colcemid (Karyomax; Invitrogen, Carlsbad, CA, USA) at $37.5^{\circ} \mathrm{C}$ in $5 \% \mathrm{CO}_{2}$ for $5 \mathrm{~h}$, then the chicken PGCs were dissociated with $0.125 \%$ trypsin- $0.02 \%$ EDTA. The cells were then centrifuged and resuspended in $0.075 \mathrm{M} \mathrm{KCl}$ solution at $37^{\circ} \mathrm{C}$. After $30 \mathrm{~min}$, the cells were centrifuged at $200 \mathrm{x} \mathrm{g}$ for $8 \mathrm{~min}$ and the pellet was fixed in 3:1 methanol: glacial acetic acid. For metaphase analysis the cell suspension was dropped on the frozen glass slides, stained with Giemsa (Amresco, Solon, $\mathrm{OH}, \mathrm{USA}$ ) and analysed for the 6 pairs of macro-chromosomes and the sex chromosomes. At least 20 metaphase spreads were counted for every chicken PGC passage.

Immunocytochemistry staining. For immunocytochemical analysis, the chicken PGCs or differentiated cells from PGCs were fixed in 4\% paraformaldehyde (PFA) in PBS and permeabilized with $0.4 \%$ Triton X-100. Blocking with $10 \%$ goat serum was performed for $1 \mathrm{~h}$ prior to the incubation with primary antibodies. The cells were incubated with primary antibodies anti-SSEA-1, BLIMP1, Oct4, Sox 2 or ACR at $4^{\circ} \mathrm{C}$ overnight, followed by goat anti-rabbit FITC or anti-mouse Alexa Fluor 594 (red)-labeled secondary antibody for $1 \mathrm{~h}$. DAPI was used to label the cell nuclei, and images were captured with a fluorescence microscope (Nikon TE-2000-E inverted microscope; Nikon, Tokyo, Japan).

RNA isolation and PCR analysis. Total RNA was extracted from the PGC colonies at third passage or induced cells after $48 \mathrm{~h}$ using TRIzol (Invitrogen). After DNase I treatment to remove the potential contamination of genomic DNA, $2.0 \mu \mathrm{g}$ of total RNA were reverse transcribed into cDNA using an RNA PCR kit (AMV) Ver.3.0 (Takara Bio Co., Dalian, China). The gene expression analysis was detected by ABI StepOnePlus Real-time PCR thermal cycling instrument (Applied Biosystems, Foster City, CA, USA). The stage specific genes CVH, BLIMP1 and the stem cell specific genes Pouv and Nanog (the primer information is shown in Table I), the Xhol repeat sequence and $18 \mathrm{~S}$ ribosomal gene (the primer information is shown in Table II) and the hallmarks of meiotic germ cells and haploid germ cell gene acrosin (ACR), DNA meiotic recombinase 1 (DMC1), BOULE, Dazl, protamine 1 (PRM1) and synaptonemal complex protein 1 (SYCP1) were detected (the primer information is shown in Table III), the PCR reactions were performed by the PCR Master Mix kit (Promega, Madison, WI, USA), and the PCR products were visualized by electrophoresis on $2.5 \%$ agarose gels. The qPCR was carried out on an ABI 7300 HT real-time PCR machine (Applied Biosystems) with the reaction volume of $30 \mu \mathrm{l}$ consisting of complementary DNA from $15 \mathrm{ng}$ of the original RNA template, $400 \mathrm{nM}$ of each of the gene-specific forward and reverse primers, and $15 \mu 1$ SYBR Premix Ex Taq (Takara Bio Co.). Then, qRT-PCR was carried out in triplicate with a SYBR Premix Ex Taq in an ABI 7500 Real-time PCR detection system (Applied Biosystems). After normalization with glyceraldehyde 3-phosphate dehydrogenase (GAPDH), relative RNA levels in the samples were calculated by the comparative threshold cycle method. The sequences of primers for PCR are listed in Table III. The $\Delta \Delta \mathrm{Ct}$ method was used to calculate relative fold-change values between samples.

Induction of sperm. The induction solution which consisted of DMEM medium replenished with 10\% FBS, $2 \%$ chicken serum and supplemented with RA and SCF were prepared. The PGCs at passage 3 were chosen and reseeded with induction solution into 24-well plates at a density of $5 \times 10^{4} / \mathrm{ml}$ in an incubator in $5 \% \mathrm{CO}_{2}$ at $37^{\circ} \mathrm{C}$. 
Table I. The primer information for PGC identification.

\begin{tabular}{|c|c|c|c|c|}
\hline Gene name & Primer sequences & Circles & Product length (bp) & $\operatorname{Tm}\left({ }^{\circ} \mathrm{C}\right)$ \\
\hline $\mathrm{CVH}$ & $\begin{array}{l}\text { F: 5'-TGGTACTAGATGAAGCAGAC-3' } \\
\text { R:5'-GATGGTAGGTTCTCTTGACA-3' }\end{array}$ & 35 & 373 & 56 \\
\hline BLIMP1 & $\begin{array}{l}\text { F: 5'-AACCGAATCAACGAGGAG-3' } \\
\text { R:5'-GTGACTGTGAGGCAACTT-3' }\end{array}$ & 35 & 249 & 55 \\
\hline POUV & $\begin{array}{l}\text { F: 5'-TTCAGCCAGACCACCATC-3' } \\
\text { R:5'-CTGCCTCATTGAGCCAAC-3' }\end{array}$ & 35 & 100 & 57 \\
\hline NANOG & $\begin{array}{l}\text { F: 5'-ATGGCTGTGGAGGATGAG-3' } \\
\text { R:5'-TGATGCCGTACAGGAGAG-3' }\end{array}$ & 35 & 209 & 56 \\
\hline GAPDH & $\begin{array}{l}\text { F: 5'-AGGTGCTGAGTATGTTGTG-3' } \\
\text { R:5'-CATGGACAGTGGTCATAAGA-3' }\end{array}$ & 35 & 269 & 55 \\
\hline
\end{tabular}

PGC, primordial germ cells; GAPDH, glyceraldehyde 3-phosphate dehydrogenase; F, forward; R, reverse.

Table II. The primer information for male and female identification.

\begin{tabular}{llcc}
\hline Gene name & \multicolumn{1}{c}{ Primer sequences } & Circles & Product length $(\mathrm{bp})$ \\
\hline Xhol & F: 5'-CCCAAATATAACACGCTTCACT-3' & 35 & 417 \\
& R: 5'-GAAATGAATTATTTTCTGGCGAC-3' & & 57 \\
18S ribosomal & F: 5'-AGCTCTTTCTCGATTCCGTG-3' & 35 & 256 \\
gene & R: 5'-GGGTAGACACAAGCTGAGCC-3' & & 60 \\
\hline
\end{tabular}

F, forward; R, reverse.

Table III. The primer information for meiotic germ cell identification.

\begin{tabular}{|c|c|c|c|c|}
\hline Gene name & Primer sequences & Circles & Product length (bp) & $\operatorname{Tm}\left({ }^{\circ} \mathrm{C}\right)$ \\
\hline \multirow[t]{2}{*}{ SYCP1 } & F: 5'-GCGTTGTCTGTGGTGATA-3' & 35 & 89 & 55 \\
\hline & R:5'-GGTTATGCTGCGTCTGAA-3' & & & \\
\hline \multirow[t]{2}{*}{ BOULE } & F: 5'-GCACAGAAGATATTACAAGAGG-3' & 35 & 108 & 55 \\
\hline & R:5'-TACATTAGAACGAGGCATCC-3' & & & \\
\hline \multirow[t]{2}{*}{ DAZL } & F: 5'-CAATATGGTACTGTGAAGGAG-3' & 35 & 126 & 54 \\
\hline & R:5'-GACACTGATCTGTGATTCTAC-3' & & & \\
\hline \multirow[t]{2}{*}{$\mathrm{ACR}$} & F: 5'-TTCTGGCTCATTGGTGTG-3' & 35 & 150 & 54 \\
\hline & R:5'-TGGATATGGCGTTGTAGTAG-3' & & & \\
\hline \multirow[t]{2}{*}{ DMC1 } & F: 5'-TCTTCGTGACATTGCTGAT-3' & 35 & 125 & 55 \\
\hline & R:5'-GGAACTTGGCTGCTACATA-3' & & & \\
\hline \multirow[t]{2}{*}{ STRA8 } & F: 5'-CAGTGGAGGTAACAGTGAG-3' & 35 & 92 & 55 \\
\hline & R:5'-AACCAGCAGCAACATCAA-3' & & & \\
\hline \multirow[t]{2}{*}{ GAPDH } & F: 5'-AACCAGCCAAGTATGATGAT-3' & 35 & 113 & 55 \\
\hline & R:5'-ACCATTGAAGTCACAGGAG-3' & & & \\
\hline
\end{tabular}

GAPDH, glyceraldehyde 3-phosphate dehydrogenase; ACR, acrosin; DMC1, DNA meiotic recombinase 1; SYCP1, synaptonemal complex protein $1 ; \mathrm{F}$, forward; R, reverse.

Flow cytometry. Flow cytometry was performed to quantify DNA content of chicken embryonal PGCs with different density of RA and SCF treatment. In brief, the samples were washed twice in PBS and fixed in cold $70 \%$ ethanol, then incubated with a solu- tion containing $25 \mu \mathrm{g} / \mathrm{ml}$ propidium iodide (PI) (Sigma-Aldrich), $40 \mu \mathrm{g} / \mathrm{ml}$ RNase (Invitrogen), and $0.3 \%$ Tween-20 in PBS at room temperature for $20 \mathrm{~min}$, cells were analyzed with a FACSCalibur system (Beckman Coulter, Brea, CA, USA). 

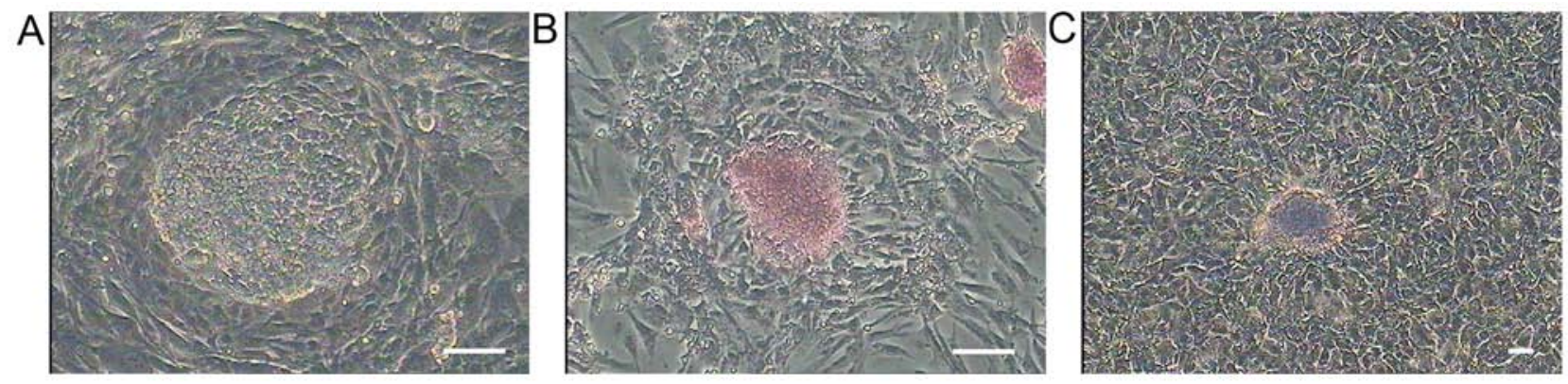

Figure 1. Morphology of primordial germ cells (PGCs). (A) On day 2 of primary culture, PGCs had a distinct 'colony' shape. (B) PGCs were stained red by PAS staining. (C) PGCs were stained mauve with AKP staining (scale bar, $100 \mu \mathrm{m}$ ).

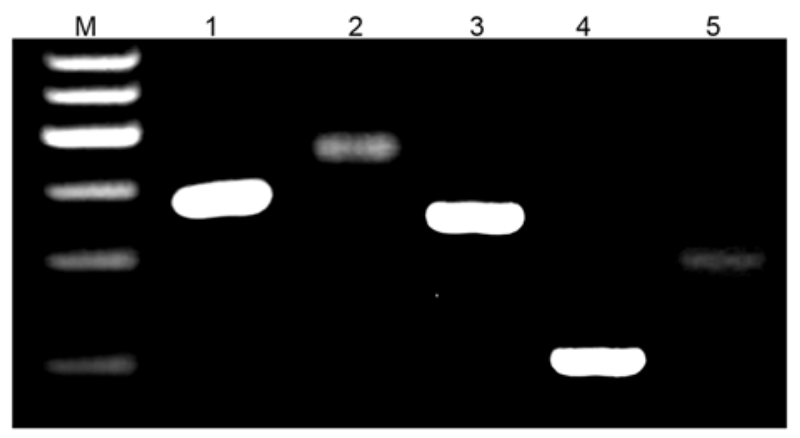

Figure 2. Detection of primordial germ cells (PGCs) markers by RT-PCR. M, marker; 1, glyceraldehyde 3-phosphate dehydrogenase (GAPDH) (269 bp); 2, CVH (373 bp); 3, BLIMP1 (249 bp); 4, POUV (100 bp); 5, NANOG (209 bp).

Statistical analysis. Statistical analyses of the data were performed with a one-way ANOVA, followed by the Tukey-Kramer honestly significant difference (HSD) test for the three sets of results. A P-value of $<0.05$ was considered statistically significant. Statistical analyses were done with a JMP Statistical Discovery software (SAS Institute, Cary, NC, USA).

\section{Results}

Characterization of PGCs. In this study, we established a stable PGC cell line (Fig. 1A) which could culture for a long time and subculture on an average of 3 days, and it supported the later sperm induction usage. The PGCs expressed the stage specific genes $\mathrm{CVH}$ and Blimp1, the stem cell specific genes Pouv and Nanog (Fig. 2), were strongly positive for AKP and PAS staining (Fig. 1B and C). We examined the three passages of PGCs which expressed stage specific surface makers SSEA-1, BLIMP1 and stem cell makers Oct 4 and Sox 2 by immunocytochemistry staining (Fig. 3), these results suggested unique characteristics for the PGCs cell line.

To distinguish whether PGC is a female or a male the W chromosome-specific Xhol family and ribosomal repeat primers previously established (17) were used. Both pairs of primers perform as expected on female and male DNA in separate reactions. The W-repeat primers produce a product only with female DNA, while the ribosomal gene primers produce a product with both male and female DNA (Fig. 4A). Furthermore, we checked the chromosome karyotype of the fourth passage. Karyotype analysis revealed that the PGCs were diploid $(2 n=78)$ with 9 pairs of macrochromosomes and 30 pairs of microchromosomes. The sex chromosome type was ZZ (Fig. 4B). PGCs karyotypes had no variation after subculture.

Effect of RA on PGCs meiosis. RA has been demonstrated to play essential roles in promoting germ cell spermatogenesis in chicken. Thus various density of RA were chosen to induce PGC cells spermatogenesis. The PGCs were treated without or with RA for differentiation. Different concentrations of RA ranging from 0.5 to $2 \mathrm{nmol} / \mathrm{ml}$, were used to optimize the condition for inducing spermatogenesis of chicken PGCs. qRT-PCR assays showed that the expression of ACR was the highest in PGCs treated with $1 \mathrm{nmol} / \mathrm{ml}$ RA compared to other concentrations of RA; the expression of SYCP1 was higher in PGCs treated with 0.5 and $1 \mathrm{nmol} / \mathrm{ml} \mathrm{RA}$ than other concentrations of RA; the expression of BOULE was higher in PGCs treated with $0.5,1$ and $2 \mathrm{nmol} / \mathrm{ml} \mathrm{RA}$ than control, and thus $1 \mathrm{nmol} / \mathrm{ml} \mathrm{RA}$ was used to induce the differentiation of chicken PGCs (Fig. 5).

$R A$ and SCF promote PGC meiotic efficiency. Previous studies evidenced that SCF was essential for the maintenance of normal spermatogenesis $(6,9)$. SCF is a cytokine that binds to the c-kit receptor which is expressed in PGCs and spermatogonia (18). SCF/c-kit plays an essential role in the regulation of spermatogenesis. Studies with type A spermatogonia have shown that SCF induces DNA synthesis and proliferation (10). Thus we added the SCF into induction solution with RA for inducement. Morphological analysis displayed a different shape of PGCs with or without RA and SCF treatment. Excitingly, more male germ cells became enlarged and elongated in PGCs treated with RA and SCF compared to the group without RA or SCF (Fig. 6A). Finally, we examined the differentiated cells which expressed sperm specific surface marker ACR by immunocytochemistry staining (Fig. 6C).

We next assessed the differentiation potential of PGCs. RT-PCR showed that the transcripts of SYCP1, BOULE, DAZL, STRA8, DMC1 and ACR, hallmarks of meiotic germ cells and haploid germ cells, respectively $(1,19)$, were enhanced in PGCs with RA and SCF treatment compared to the control without SCF and RA (Fig. 6B), and real-time PCR revealed that the mRNA levels of SYCP1, BOULE, DMC1 and ACR were significantly upregulated in PGCs with RA and SCF treatment compared to the control without SCF or RA (Fig. 7). Considered the above, these results evidence that RA and SCF 


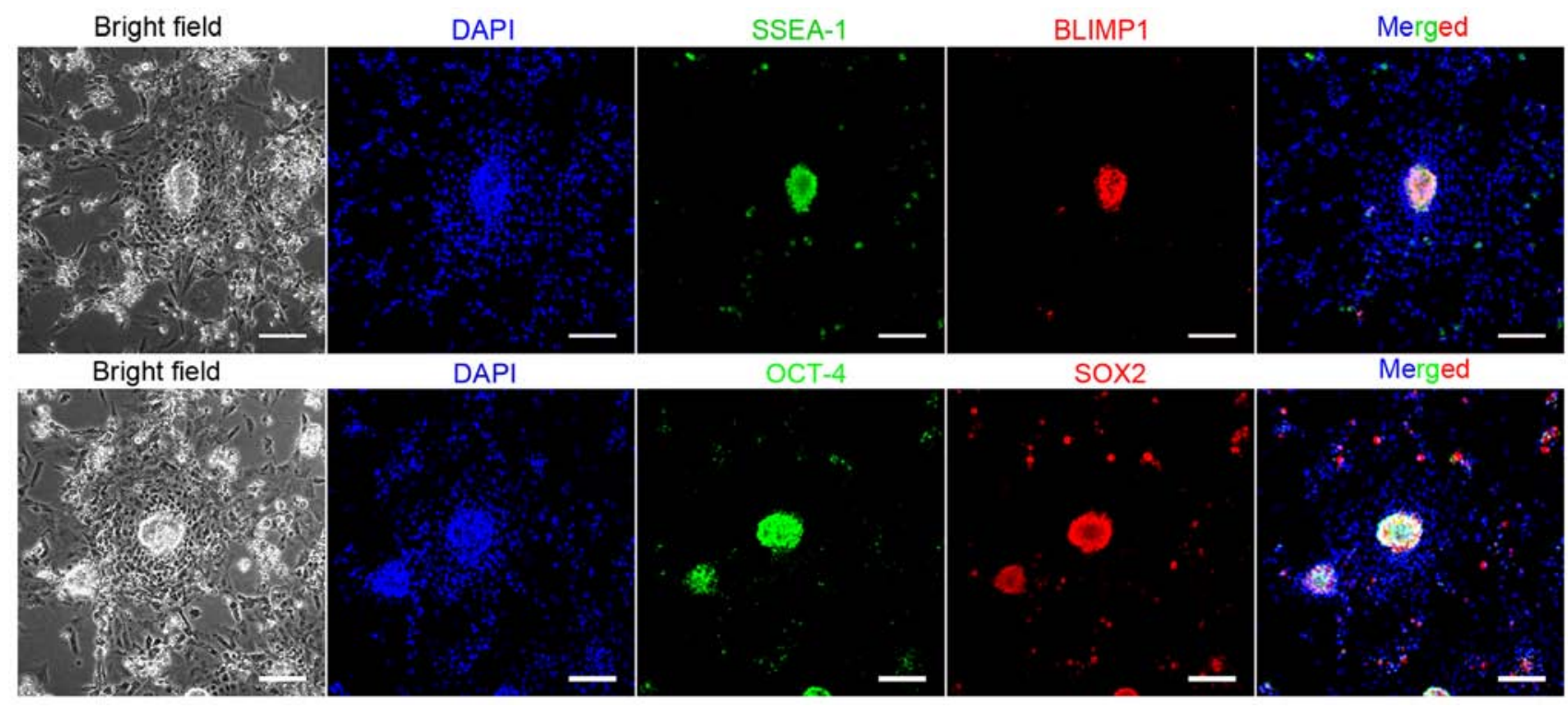

Figure 3. Surface marker detection of chicken primordial germ cells (PGCs) by immunofluorescence staining. The results show that SSEA-1, BLIMP1, Oct4 and Sox 2 are positively expressed (scale bar, $100 \mu \mathrm{m}$ ).

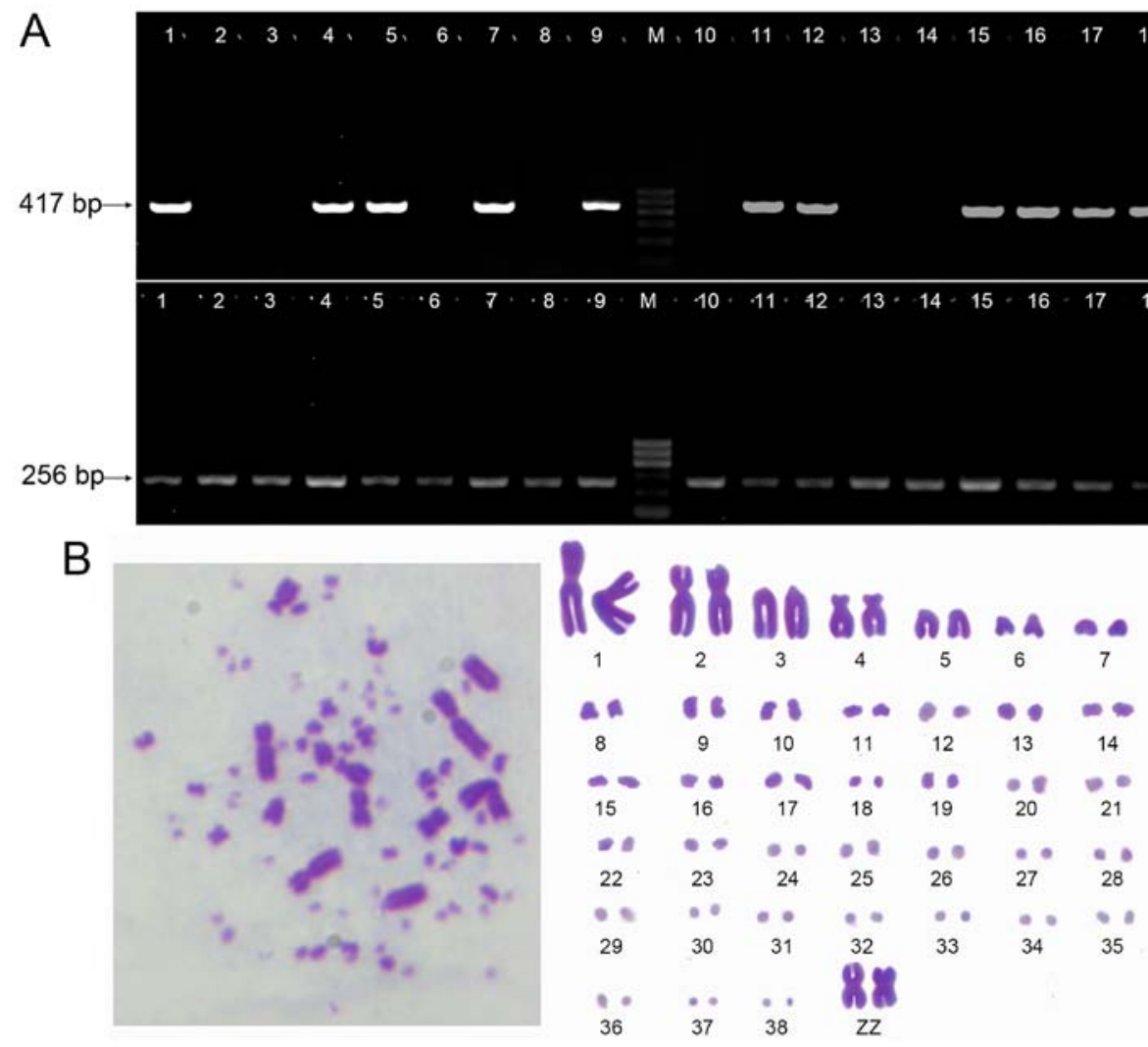

Figure 4. Identification of male and female primordial germ cells (PGCs). (A) Specificity of PCR primers. PCR reactions were performed using W-repeat (417 bp) or $18 \mathrm{~S}$ ribosomal gene (256 bp) primers on female and male DNA. 1-18: The DNA samples were respectively extracted from 18 chicken embryos; 2,3 , 6, 8 10,13 and 14 were male chicken embryos; M, marker. (B) Chromosome at metaphase (left) and karyotype (right) of chicken PGCs ( $\left.{ }^{\lambda}\right)$ ZZ type. The diploid chromosome number in chicken PGCs was $2 n=78$, consisting of 9 pairs of macrochromosomes and 30 pairs of microchromosomes.

promote the differentiating efficiency of chicken PGCs into meiotic male germ cells and haploid cells at transcriptional level.

$R A$ and SCF induce increase of haploid cell population. To evaluate the ploidy levels of chicken PGCs without or with
RA and SCF treatment, flow cytometry were used to analyze DNA contents. Notably, the haploid cells originated from 10.8 to $15.5 \%$ in PGCs with RA treatment, $18.3 \%$ in PGCs with RA and SCF treatment compared to the control (Fig. 8). These data further implicate that RA and SCF improve the differentiating efficiency of PGCs into haploid spermatids. 

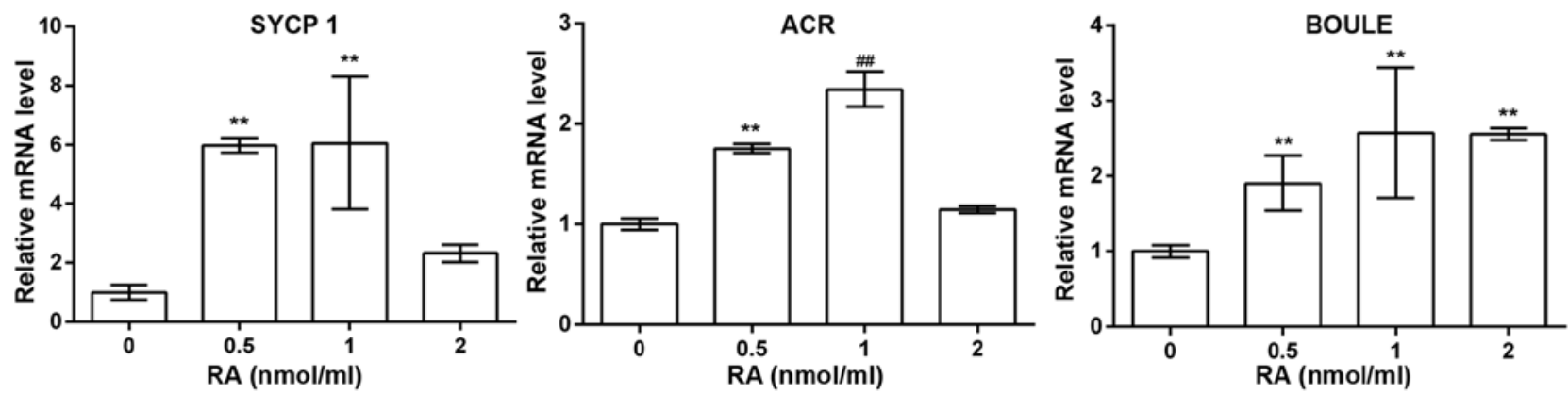

Figure 5. Real-time RT-PCR revealed mRNA expression of synaptonemal complex protein 1 (SYCP1) $(1.00 \pm 0.25,5.98 \pm 0.26,6.06 \pm 2.25,2.32 \pm 0.30, \mathrm{n}=3$ ), acrosin (ACR) $(1.00 \pm 0.06,1.76 \pm 0.05,2.34 \pm 0.18,1.14 \pm 0.03, \mathrm{n}=3)$, and BOULE $(1.00 \pm 0.09,1.90 \pm 0.36,2.58 \pm 0.86,2.56 \pm 0.08, \mathrm{n}=3)$ in primordial germ cells $(\mathrm{PGCs})$ treated with $0,0.5,1$ and $2 \mathrm{nmol} / \mathrm{ml}$ of retinoic acid (RA), respectively. ${ }^{* *} \mathrm{P}<0.01$ compared with $0 \mathrm{nmol} / \mathrm{ml}$ of RA; ${ }^{\# \#} \mathrm{P}<0.01 \mathrm{compared}$ with $0.5 \mathrm{nmol} / \mathrm{ml}$ of RA.

A

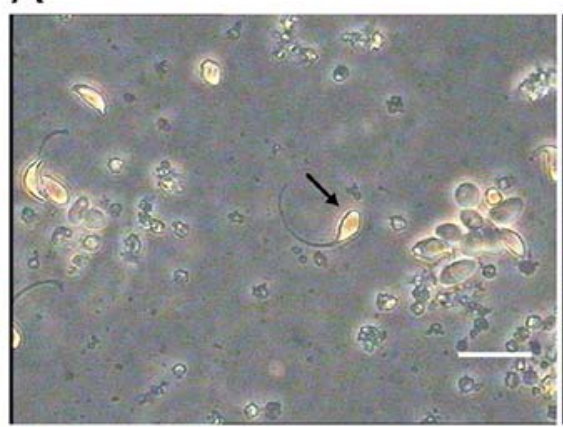



\section{B}
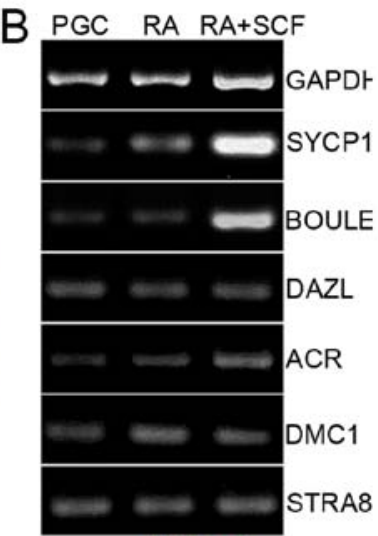

Merged


Figure 6. Induction of sperm. (A) Morphology of induced sperms (indicated by arrows) from primordial germ cells (PGCs). (B) RT-PCR showed mRNA expression of synaptonemal complex protein 1 (SYCP1) (89 bp), BOULE (108 bp), DAZL (126 bp), acrosin (ACR) (150 bp), DNA meiotic recombinase 1 (DMC1) (125 bp) and STRA8 (92 bp) in chicken PGCs without or with stem cell factor (SCF) and RA treatment. Glyceraldehyde 3-phosphate dehydrogenase (GAPDH) (113 bp) was used as a loading control of total RNA. (C) Immunocytochemistry displayed ACR expression of induced sperms (scale bar, $50 \mu \mathrm{m}$ ).

\section{Discussion}

We examined the efficiency of in vitro expansion of chicken PGCs which were cultured for 6 weeks. Establishment of the long-term in vitro culture system for PGCs could provide numerous cells for research (20). In our culture system the PGCs were strongly positive for AKP and PAS staining $(21,22)$ and its karyotype kept no variation after subculture. The size of PGCs, large amounts of glycogen granules in the cytoplasm and large nuclei, are bigger than somatic cells. This result implicated that the PGC wants normal growth and development.

To obtain conclusive evidence that the PGCs were derived from male chicken embryos, we investigated whether these cells presented female or male phenotypes. The female and male gonads of the chicken embryos developed at stage 28 are morphologically similar known as the indifferent gonad. Gonads of female and male, respectively, develop into ovarian and testicular characteristics after the indifferent stage. Previous studies demonstrated a kind of repetitive DNA sequences from $\mathrm{W}$ chromosome present specifically in the female chicken $(17,23)$. Thus, we evidenced that a PCR reaction, containing primers specific to both the $\mathrm{W}$ chromosome sequence and the $18 \mathrm{~S}$ ribosomal gene, can readily make a clear distinction between female and male DNA. The karyotype analysis is also an important research means of cytogenetics. It can not only quickly identify mutated chromosomes, but also distinguish male and female phenotypes $(6,24)$. Combining these two methods, we were able to separate the male PGCs from chicken embryos.

RA has been shown to be a meiosis-inducing substance. Several studies have suggested the importance of RA in germ cell meiotic initiation $(6,9,25)$. Our results suggested, in agree- 

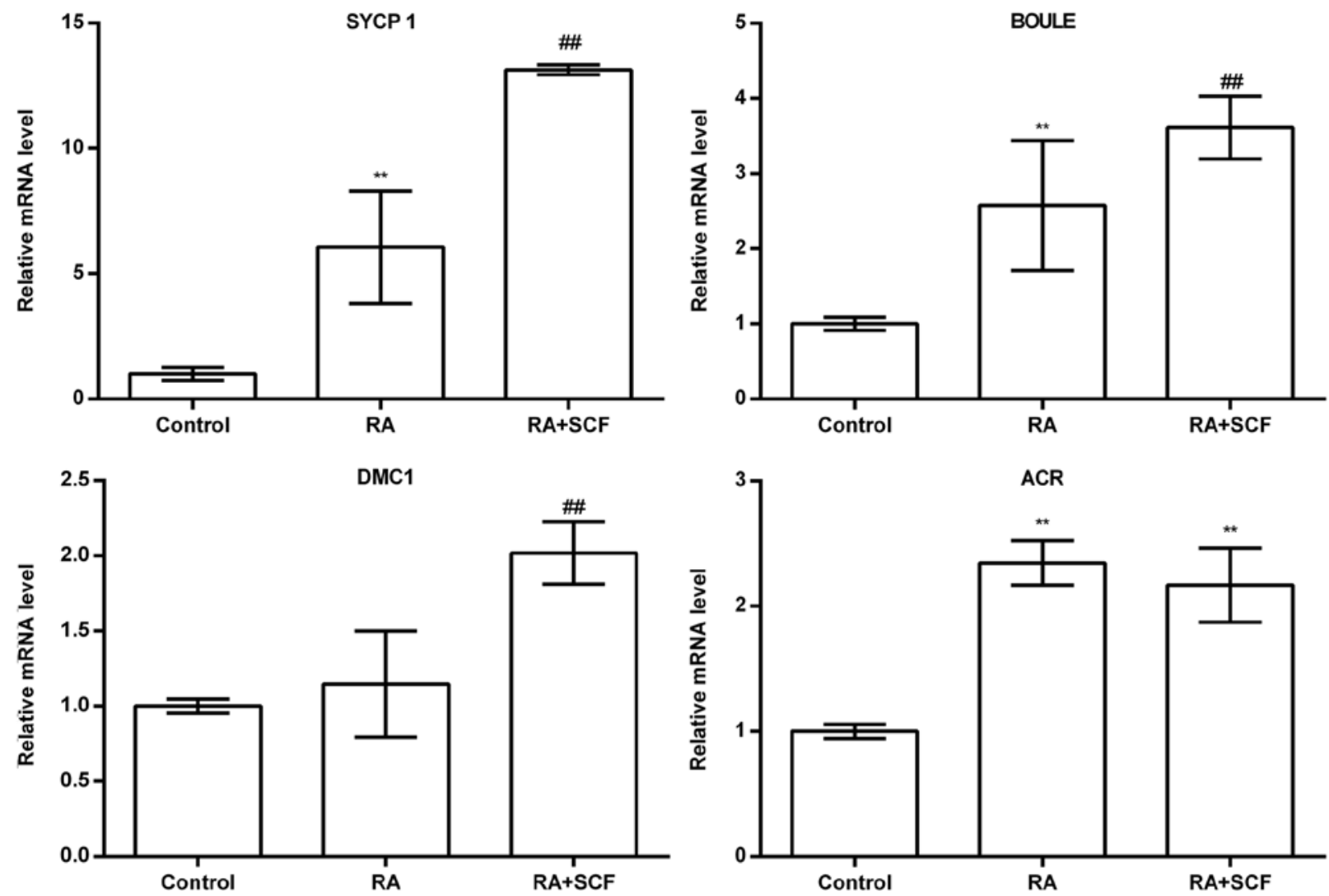

Figure 7. Real-time RT-PCR revealed mRNA expression of synaptonemal complex protein 1 (SYCP1) $(1.00 \pm 0.25,6.06 \pm 2.25,13.14 \pm 0.19$, $\mathrm{n}=3$ ), BOULE $(1.00 \pm 0.09,2.58 \pm 0.86,3.61 \pm 0.42, \mathrm{n}=3)$, DNA meiotic recombinase 1 (DMC1) $(1.00 \pm 0.04,1.14 \pm 0.35,2.02 \pm 0.21, \mathrm{n}=3)$, and acrosin $(\mathrm{ACR})(1.00 \pm 0.06,2.34 \pm 0.18$, $2.16 \pm 0.30, \mathrm{n}=3$ ) in primordial germ cells (PGCs) treated without retinoic acid (RA) and stem cell factor (SCF), with RA, and with RA and SCF, respectively. ${ }^{* *} \mathrm{P}<0.01$ compared with control; ${ }^{\# \#} \mathrm{P}<0.01$ compared with RA.
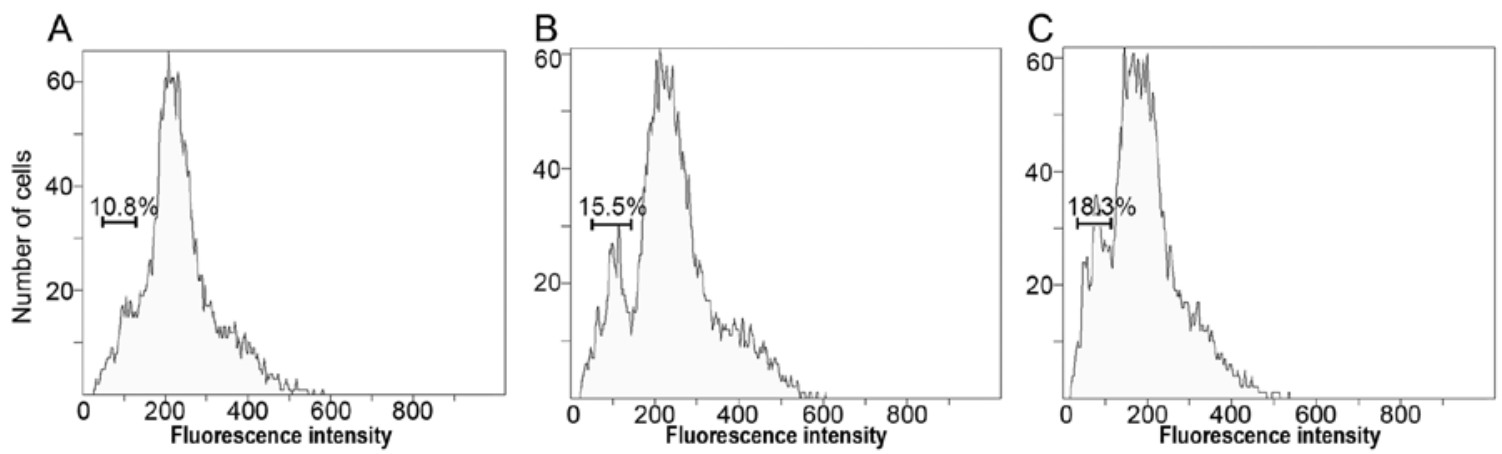

Figure 8. Flow cytometry showing DNA content in the haploid cells differentiated from primordial germ cells (PGCs) without retinoic acid (RA) and stem cell factor (SCF) treatment (A) (10.8\%), RA treatment (B) (15.5\%) or with SCF and RA treatment (C) $(18.3 \%)$.

ment with previous studies, that $1 \mathrm{nmol} / \mathrm{ml}$ RA induced PGC meiosis efficiently. SSCs originate from PGCs. During avian and mammalian development, PGCs migrate along the dorsal mesentery into the genital ridges, and their differentiation lasts several weeks $(26,27)$, while PGC differentiation into spermatigonia and spermatigonia to reach the haploid sperm needs a long time-period (28). SCF has been reported to be crucial in spermatogonial differentiation as well as meiotic initiation (10). Our results indicated that RA and SCF promote the greater differentiating efficiency of chicken PGCs into meiotic male germ cells and haploid cells then RA was induced. Crosstalk between RA and the SCF pathway stimulated differentiation of male germ cells toward the meiotic stages (29).
Various types of detection methods, including quantitative PCR, RT-PCR and FACS assays were used to assess the differentiation potential of chicken PGCs. The expression of several genes for meiotic and haploid cells, including SYCP1, BOULE, DMC1 and ACR $(1,6)$, in chicken PGCs were evidently upregulated after treatment with RA and SCF. SYCP1, major component of the transverse filaments of synaptonemal complexes (SCS), can be used to measure the synaptonemal complex, which formed between homologous chromosomes during meiotic prophase (30). BOULE, with a key role in germ cell development, is a member of the DAZ gene family. Loss of this gene function results in azoospermia. Previous studies found that they originally appeared in the meiotic G2/M transition (31). 
DMC1 encodes the DNA strand-exchange protein, which is essential for repairing double-strand DNA breaks during mitosis and meiosis and meiotic homologous recombination (32). ACR, a typical serine proteinase with trypsin-like specificity, is the key proteinase present in the acrosome of mature spermatozoa. Research demonstrated that the mRNA for proacrosin is expressed only in the postmeiotic stages of spermatogenesis (33). The DNA content of chicken PGCs with RA and SCF treatment was detected by FACS. Although the DNA ploidy levels show that PGCs have the ability of spontaneous differentiation into haploid cells, the number of haploid cells was obviously increased in chicken PGCs by RA and SCF treatment. These markers for meiosis and postmeiosis obviously show that RA and SCF promote the differentiation of chicken PGCs into the postmeiotic stage and finally differentiate into haploid spermatids.

In this study, we evidenced that RA and SCF are effective in promoting the differentiation of chicken PGCs from gonadal ridges into cells with phenotypic features, and DNA content of haploid spermatids. This study thus offers an approach to generate functional haploid spermatids from PGCs, which could provide male gametes for clinical treatment and transgenic animal research.

\section{Acknowledgements}

This study was supported by the National Natural Science Foundation of China (no. 31472099).

\section{Competing interests}

The authors declare there is no competing interest.

\section{References}

1. Mi Y, He B, Li J and Zhang C: Progesterone regulates chicken embryonic germ cell meiotic initiation independent of retinoic acid signaling. Theriogenology 82: 195-203, 2014.

2. Feng LX, Chen Y, Dettin L, Pera RA, Herr JC, Goldberg E and Dym M: Generation and in vitro differentiation of a spermatogonial cell line. Science 297: 392-395, 2002.

3. Saitou M and Yamaji M: Germ cell specification in mice: Signaling, transcription regulation, and epigenetic consequences. Reproduction 139: 931-942, 2010.

4. Martinovitch PN: Development in vitro of the mammalian gonad. Nature 139: 413, 1937

5. Dann CT, Alvarado AL, Molyneux LA, Denard BS, Garbers DL and Porteus MH: Spermatogonial stem cell self-renewal requires OCT4, a factor downregulated during retinoic acid-induced differentiation. Stem Cells 26: 2928-2937, 2008.

6. Yang S, Ping P, Ma M, Li P, Tian R, Yang H, Liu Y, Gong Y, Zhang Z, Li Z, et al: Generation of haploid spermatids with fertilization and development capacity from human spermatogonial stem cells of cryptorchid patients. Stem Cell Rep 3: 663-675, 2014

7. Childs AJ, Cowan G, Kinnell HL, Anderson RA and Saunders PT: Retinoic Acid signalling and the control of meiotic entry in the human fetal gonad. PLoS One 6: e20249, 2011.

8. Ohta K, Lin Y, Hogg N, Yamamoto M and Yamazaki Y: Direct effects of retinoic acid on entry of fetal male germ cells into meiosis in mice. Biol Reprod 83: 1056-1063, 2010.

9. Bowles J, Knight D, Smith C, Wilhelm D, Richman J, Mamiya S, Yashiro K, Chawengsaksophak K, Wilson MJ, Rossant J, et al: Retinoid signaling determines germ cell fate in mice. Science 312: 596-600, 2006

10. Feng LX, Ravindranath N and Dym M: Stem cell factor/c-kit upregulates cyclin D3 and promotes cell cycle progression via the phosphoinositide 3-kinase/p70 S6 kinase pathway in spermatogonia. J Biol Chem 275: 25572-25576, 2000.

11. Mithraprabhu S and Loveland KL: Control of KIT signalling in male germ cells: What can we learn from other systems? Reproduction 138: 743-757, 2009.
12. Smith CA, Roeszler KN, Bowles J, Koopman P and Sinclair AH: Onset of meiosis in the chicken embryo; evidence of a role for retinoic acid. BMC Dev Biol 8: 85, 2008.

13. Zhou Q, Li Y, Nie R, Friel P, Mitchell D, Evanoff RM, Pouchnik D, Banasik B, McCarrey JR, Small C, et al: Expression of stimulated by retinoic acid gene 8 (Stra8) and maturation of murine gonocytes and spermatogonia induced by retinoic acid in vitro. Biol Reprod 78: 537-545, 2008.

14. Hamburger V and Hamilton HL: A series of normal stages in the development of the chick embryo. J Morphol 88: 49-92, 1951.

15. Choi JW, Kim S, Kim TM, Kim YM, Seo HW, Park TS, Jeong JW, Song G and Han JY: Basic fibroblast growth factor activates MEK/ ERK cell signaling pathway and stimulates the proliferation of chicken primordial germ cells. PLoS One 5: e12968, 2010.

16. Liu CX, Wang WL, Zhao RY, Wang HT, Liu YY, Wang SY and Zhou HM: Isolation, culture, and characterization of primordial germ cells in Mongolian sheep. In Vitro Cell Dev Biol Anim 50: 207-213, 2014.

17. Clinton M, Haines L, Belloir B and McBride D: Sexing chick embryos: A rapid and simple protocol. Br Poult Sci 42: 134-138, 2001 .

18. RossiP,Sette C,DolciS and Geremia R: Role of c-kit in mammalian spermatogenesis. J Endocrinol Invest 23: 609-615, 2000.

19. West JA, Park IH, Daley GQ and Geijsen N: In vitro generation of germ cells from murine embryonic stem cells. Nat Protoc 1: 2026-2036, 2006.

20. Shiue YL, Tailiu JJ, Liou JF, Lu HT, Tai C, Shiau JW and Chen LR: Establishment of the long-term in vitro culture system for chicken primordial germ cells. Reprod Domest Anim 44: 55-61, 2009.

21. Jung JG, Kim DK, Park TS, Lee SD, Lim JM and Han JY: Development of novel markers for the characterization of chicken primordial germ cells. Stem Cells 23: 689-698, 2005.

22. Wang Y, Hou L, Li C, Guan W, Chen L, Li X, Yue W and Ma Y: Isolation, culture and biological characteristics of primordial germ cells from Beijing fatty chicken. J Reprod Dev 56: 303-308, 2010.

23. Tone M, Nakano N, Takao E, Narisawa S and Mizuno S: Demonstration of $\mathrm{W}$ chromosome-specific repetitive DNA sequences in the domestic fowl, Gallus g. domesticus. Chromosoma 86: $551-569,1982$.

24. Nishida C, Ishijima J, Ishishita S, Yamada K, Griffin DK, Yamazaki T and Matsuda Y: Karyotype reorganization with conserved genomic compartmentalization in dot-shaped microchromosomes in the Japanese mountain hawk-eagle (Nisaetus nipalensis orientalis, Accipitridae). Cytogenet Genome Res 141: 284-294, 2013.

25. Eguizabal C, Montserrat N, Vassena R, Barragan M, Garreta E, Garcia-Quevedo L, Vidal F, Giorgetti A, Veiga A and Izpisua Belmonte JC: Complete meiosis from human induced pluripotent stem cells. Stem Cells 29: 1186-1195, 2011.

26. Childs AJ and Anderson RA: Experimental approaches to the study of human primordial germ cells. Methods Mol Biol 825: 199-210, 2012.

27. Macdonald J, Glover JD, Taylor L, Sang HM and McGrew MJ: Characterisation and germline transmission of cultured avian primordial germ cells. PLoS One 5: e15518, 2010.

28. Amann RP: The cycle of the seminiferous epithelium in humans: A need to revisit? J Androl 29: 469-487, 2008.

29. Pellegrini M, Filipponi D, Gori M, Barrios F, Lolicato F, Grimaldi P, Rossi P, Jannini EA, Geremia R and Dolci S: ATRA and KL promote differentiation toward the meiotic program of male germ cells. Cell Cycle 7: 3878-3888, 2008.

30. Türeci O, Sahin U, Zwick C, Koslowski M, Seitz G and Pfreundschuh M: Identification of a meiosis-specific protein as a member of the class of cancer/testis antigens. Proc Natl Acad Sci USA 95: 5211-5216, 1998.

31. Kee K, Angeles VT, Flores M, Nguyen HN and Reijo Pera RA: Human DAZL, DAZ and BOULE genes modulate primordial germ-cell and haploid gamete formation. Nature 462: 222-225, 2009.

32. Habu T, Taki T, West A, Nishimune Y and Morita T: The mouse and human homologs of DMC1, the yeast meiosis-specific homologous recombination gene, have a common unique form of exon-skipped transcript in meiosis. Nucleic Acids Res 24: 470-477, 1996.

33. Zahn A, Furlong LI, Biancotti JC, Ghiringhelli PD, MarijnBriggiler CI and Vazquez-Levin MH: Evaluation of the proacrosin/acrosin system and its mechanism of activation in human sperm extracts. J Reprod Immunol 54: 43-63, 2002.

This work is licensed under a Creative Commons Attribution-NonCommercial-NoDerivatives 4.0 International (CC BY-NC-ND 4.0) License. 